Contract No. and Disclaimer:

This manuscript has been authored by Savannah River Nuclear Solutions, LLC under Contract No. DE-AC09-08SR22470 with the U.S. Department of Energy. The United States Government retains and the publisher, by accepting this article for publication, acknowledges that the United States Government retains a non-exclusive, paid-up, irrevocable, worldwide license to publish or reproduce the published form of this work, or allow others to do so, for United States Government purposes. 
SRNL-STI-2010-00033

\title{
TCAP HYDROGEN ISOTOPE SEPARATION USING PALLADIUM AND INVERSE COLUMNS
}

\author{
L. K. Heung*, H. T. Sessions, and S. Xiao
}

Savannah River National Laboratory, 999-2W, Savannah River Site, Aiken SC 29808 USA leung.heung@srnl.doe.gov

The Thermal Cycling Absorption Process (TCAP) was further studied with a new configuration. Previous configuration used a palladium packed column and a plug flow reverser (PFR). This new configuration uses an inverse column to replace the PFR. The goal was to further improve performance. Both configurations were experimentally tested. The results showed that the new configuration increased the throughput by a factor of more than 2.

\section{INTRODUCTION}

TCAP, a Thermal Cycling Absorption Process for hydrogen isotope separation, was first described by Dr. M. W. Lee in the 1986 Gordon Research Conference held in Oxnard, CA (USA) (Ref. 1). There were several publications in subsequent years with performance data. $^{2,3}$. Recently, the process was improved by a compact thermal cycling concept, in which the column design was changed so that the extensive heating and cooling equipment was replaced by small electric heaters and liquid nitrogen cooling tubes. The change reduced the foot print of the process equipment by a factor of 10 (Ref. 4 and 5). This present work made another step improvement in performance of the process by replacing the plug flow reverser with an inverse column.

TCAP uses the isotopic effect of palladium absorption of hydrogen isotopes. It is well known in the tritium community that palladium absorbs hydrogen isotopes and exhibits different equilibrium pressures in the order of tritium>deuterium>protium. The differences in equilibrium pressures are also temperature dependent; they decrease as temperature increases. The conventional TCAP process consists of a $\mathrm{Pd} / \mathrm{k}$ (palladium deposited on kieselguhr) packed column and a plug flow reverser (PFR) which is a larger diameter but shorter column packed with kieselguhr to enhance its plug flow characteristics. In operation, the $\mathrm{Pd} / \mathrm{k}$ column temperature is cycled and the PFR stays at ambient temperature. During the cold phase of the cycle, as gas flow from the PFR to the $\mathrm{Pd} / \mathrm{k}$ column, the heavier isotope is concentrated in the flow front. During the hot phase of the cycle, gas flows from the Pd/k column to the PFR and the concentration profile is mostly preserved due to the smaller isotopic effect at high temperature and the plug flow characteristic of the PFR. Also in every cycle, feed is introduced at the mid point of the $\mathrm{Pd} / \mathrm{k}$ column during the cold phase, and product (heavy isotope) and raffinate (light isotope) are removed from opposite ends of the $\mathrm{Pd} / \mathrm{k}$ column during the hot phase.

Note that the PFR just provides a volume for the Pd/k column to regenerate. It is otherwise passive and does not provide any separation of the isotopes. Therefore, the conventional TCAP can easily produce high purity heavy isotope (product) but it can not easily produce high purity light isotope (raffinate). If the PFR were replaced with an active column that could function as the PFR and also provide opposite isotopic effect of the palladium column, then this process would produce high purity raffinate as well as high purity product. Such an active column would be called the inverse column. Several types of molecular sieves are known to adsorb large amounts of hydrogen at liquid nitrogen temperature and to exhibit different equilibrium pressures of the hydrogen isotopes in the order of protium $>$ deuterium $>$ tritium, which is opposite to that of Pd (Ref. 6). In this study, molecular sieve type 4A (MS4A) was selected as a packing material for an inverse column to replace the PFR. This paper presents experimental results showing that the replacement of the PFR with this inverse column doubled the process throughput.

\section{EQUIPMENT AND METHOD}

A Pd/k packed column, a kieselguhr packed passive plug flow reverser (PFR) and a MS4A packed active inverse column (MS column) were used in this study. Other components included three calibrated volumes, a residue gas analyzer (RGA) (Pfeiffer Prisma model QME 200), and a computer for process control and data acquisition.

The $\mathrm{Pd} / \mathrm{k}$ column was fabricated from copper tubing, $0.95 \mathrm{~cm}$ (3/8”) diameter and $6.35 \mathrm{~m}$ (20' 11”) long. The column was traced with electric heaters (ARi Industries 
Inc.) for heating and $0.635 \mathrm{~cm}$ (1/4”) copper tubing for liquid nitrogen cooling. The column assembly was folded in the shape of a paper clip to reduce the overall height, and is thermally insulated. Figure 1(a) is a picture of the $\mathrm{Pd} / \mathrm{k}$ column before it was insulated.

The inverse column was fabricated from stainless steel tubing of the same size as the $\mathrm{Pd} / \mathrm{k}$ column but is only $3.33 \mathrm{~m}$ (10' 11”) long. It was filled with 99 grams of molecular sieve type 4A dried. The material was purchased from Sigma Aldrich in the form of $0.368 \mathrm{~cm}(1 / 8$ ") pellets which was ground to 30 -

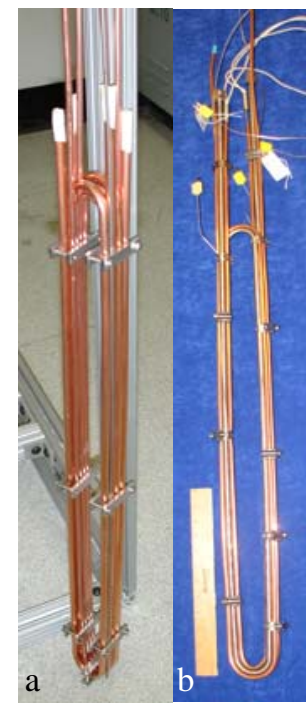

Figure 1. Pd/k and MS columns 50 mesh for use in the column.

Stainless steel was used because its high working pressure was needed for pressure safety. The liquid nitrogen cooling tube was still copper. Figure 1 (b) is a picture of the MS column before it was insulated.

The plug flow reverser (PFR) was formed by two $0.91 \mathrm{~m}$ long sections of $5.1 \mathrm{~cm}$ diameter stainless steel pipes connected to make a $1.82 \mathrm{~m}, 2.5$ liter volume. It was filled with kieselguhr to enhance the plug flow property.

To remove moisture and adsorbed impurities, the $\mathrm{Pd} / \mathrm{k}$ column and the PFR were baked out at $150{ }^{\circ} \mathrm{C}$ for about 16 hour using hydrogen purge, and the MS column was baked out at $450{ }^{\circ} \mathrm{C}$ for 184 hours using helium purge.

The effective separation stages of the $\mathrm{Pd} / \mathrm{k}$ column and the MS column were determined using a pulse test method that was published in an earlier paper (Ref. 7). Using this method the height equivalent of theoretical

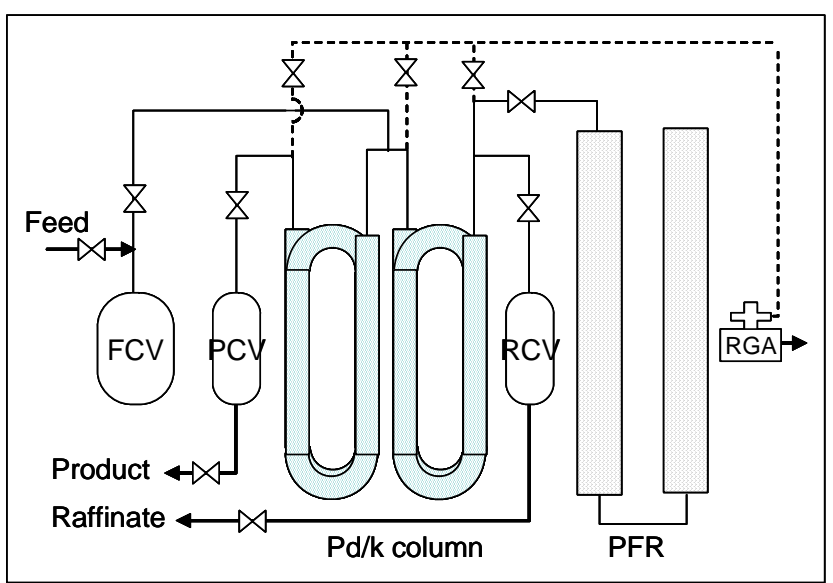

Figure 2. The Pd/k-PFR configuration. plate (HETP), which is a parameter representing the length in a column to achieve one stage of equilibrium, was calculated.

For the Pd/k-PFR configuration, the Pd/k column and the PFR was connected as shown in Figure 2. Feed is introduced at the mid point of the $\mathrm{Pd} / \mathrm{k}$ column. Product $\left(\mathrm{D}_{2}\right)$ and raffinate $\left(\mathrm{H}_{2}\right)$ are taken from opposite ends of the $\mathrm{Pd} / \mathrm{k}$ column. Calibrated volumes, FCV, PCV and RCV are used to measure the quantity of feed, product and raffinate.

To begin gas separation tests, the $\mathrm{Pd} / \mathrm{k}$ column was loaded with 4 STP liters of $D_{2}$ at the product end and 4 STP liters of $\mathrm{H}_{2}$ at the raffinate end. The PFR was loaded with 7 STP liters of $\mathrm{H}_{2}$. The test started in the total reflux mode, in which no feed was introduced, nor product and raffinate taken, for about 10 cycles to establish a steady concentration profile in the column with high purity $\mathrm{D}_{2}$ in the product end and high purity $\mathrm{H}_{2}$ in the raffinate end. Then the operation would enter the online mode in which feed was introduced and product and raffinate were taken in every cycle. A cycle consisted of a cooling phase and a heating phase. In the cooling phase the $\mathrm{Pd} / \mathrm{k}$ column was cooled to approximately $-50^{\circ} \mathrm{C}$ by flowing liquid nitrogen through the cooling tubes. This low temperature reduced the column pressure to below 5 torr. Feed was introduced at the mid point of the $\mathrm{Pd} / \mathrm{k}$ column, the valve between the column and the PFR was then opened to transfer about 3.5 liters of gas to the column. This valve was closed and the column was switched from cooling to heating. When the temperature reached about $120^{\circ} \mathrm{C}$ the column pressure increased to approximately 5000 torr. Product and raffinate were taken and then a valve is opened to transfer about 3.5 liter gas back from the Pd/k column to the PFR. This cycle was then repeated. The gas compositions at the mid column feed point, the product end and the raffinate end were sampled each cycle by the RGA. Product and raffinate quantities were removed in such a way that the column inventory stayed constant.

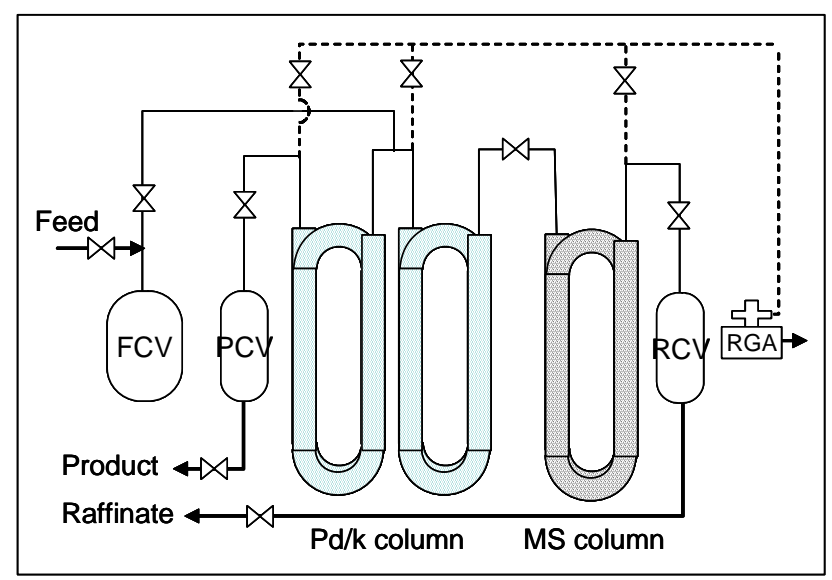

Figure 3. The Pd/k-MS configuration. 
For the $\mathrm{Pd} / \mathrm{k}$-MS configuration the columns were connected as shown in Figure 3. Note that the feed point did not change, but the raffinate withdraw point was moved to the far end of the MS column. The MS column was loaded with about 10 STP liters of protium for startup. Operation of this configuration was similar to the $\mathrm{Pd} / \mathrm{k}$-PFR configuration, except that the PFR was replaced with the MS column. The active MS column required temperature cycling. During heating phase of the $\mathrm{Pd} / \mathrm{k}$ column the MS column was cooled to near liquid nitrogen temperature $\left(-190{ }^{\circ} \mathrm{C}\right)$. At this point in the cycle product was withdrawn from the $\mathrm{Pd} / \mathrm{k}$ column. During cooling phase of the $\mathrm{Pd} / \mathrm{k}$ column the MS column was warmed to about $-100{ }^{\circ} \mathrm{C}$. Feed was then introduced at the mid point of the $\mathrm{Pd} / \mathrm{k}$ column and raffinate was withdrawn from the MS column.

\section{RESULTS AND DISCUSSIONS}

\section{III.A. Separation Stages of the columns}

We had learned in previous experiments that the staging efficiency of a $\mathrm{Pd} / \mathrm{k}$ column is a function of column diameter and flow rate. We had also learned that 120 stages are required to achieve satisfactory performance of a $\mathrm{Pd} / \mathrm{k}$ column in the TCAP process. ${ }^{4,7}$ Therefore tests were conducted to confirm that this experimental $\mathrm{Pd} / \mathrm{k}$ column would provide the required number of stages. Test results are compared with those reported in references 4 and 7 in Figure 4. The test data confirmed that small diameter reduces HETP, and it also confirmed that this smaller column provided the needed 120 or more stages (HETP $5.29 \mathrm{~cm} / \mathrm{stage}$ ) for flow rates not higher than approximately $800 \mathrm{~cm} / \mathrm{min}$. This rate is

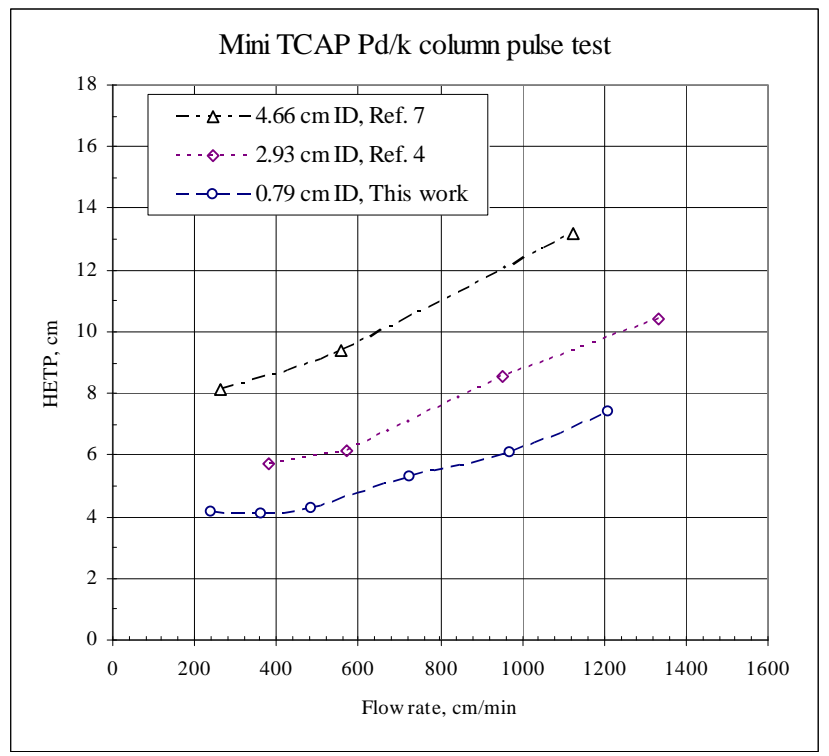

Figure 4. Staging efficiency of Pd/k columns

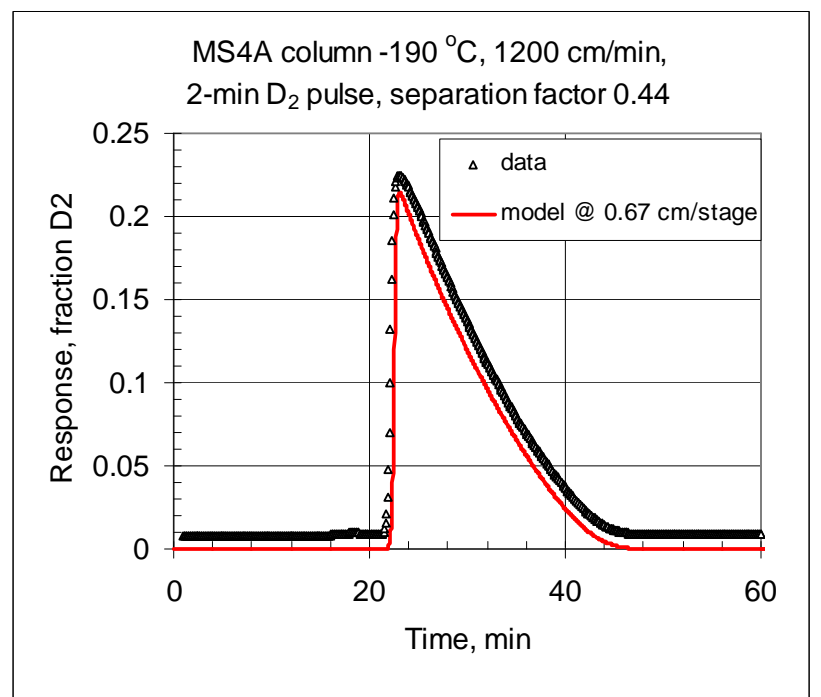

Figure 5. Staging efficiency of the MS column.

equivalent to $0.5 \mathrm{STP}$ liter/min which was sufficient for this study.

A similar test was conducted on the MS column to determine its HETP. The test results showed that the MS column was very effective and the HETP is only 0.67 $\mathrm{cm} / \mathrm{stage}$ even at a high flow rate of $1.2 \mathrm{~m} / \mathrm{min}$. Figure 5 is a set of the pulse data that matched the model calculation very well. This MS column provided 500 stages which was more than sufficient for this study.

\section{III.B. Pd/k-PFR Configuration}

The process was run in the total reflux mode (no feed) for about 10 cycles before the online mode was started. The temperature and pressure profiles of a typical cycle are shown in Figure 6 . The $\mathrm{Pd} / \mathrm{k}$ column temperature was cycled between -80 and $+170{ }^{\circ} \mathrm{C}$. Its pressure cycled from approximately 1 to 4800 torr. The PFR pressure cycled from 1250 to 2100 torr. The feed rate was increased in steps from 1 STP liter/cycle to 2 and 3 STP liter/cycle. Each feed rate was given at least 10 cycles to reach steady state. Product $\left(D_{2}\right)$ and raffinae $\left(\mathrm{H}_{2}\right)$ purity data are present in Figure 7. The data showed that the purities stayed at better than $98 \%$ for both streams until the feed rate was increased to 3 STP liter/cycl. At this rate the product purity was still good but the raffinate purity began to deteriorate after 6 cyles, and reached $80 \%$ after 9 cycles. The product purity remained good at this rate.

\section{III.C. Pd/k-MS Configuration}

Following the Pd/k-PFR configuration tests, the PFR was replaced with the MS column and the tests continued in the online mode at $1 \mathrm{STP}$ L/cycle. After 22 cycles the 


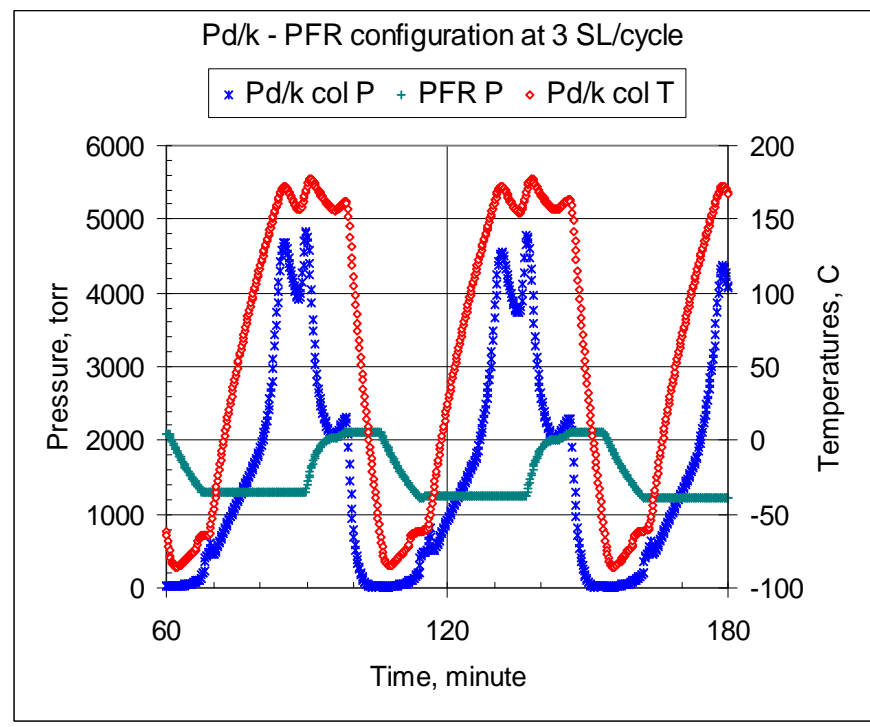

Figure 6. Temperature and pressure profiles of Pd/k-PFR configuration.

feed rate was increased in steps to 2, 3 and 4 STP L/cycle. Twelve or more cycles were run for each of the 1,3 and 4 STP L/cycle feed rates. Typical temperature and pressure profiles are shown in Figure 8 . The $\mathrm{Pd} / \mathrm{k}$ column temperature ranged from -70 to $+145{ }^{\circ} \mathrm{C}$ and pressure from 1 torr to 5500 torr. The MS column temperature ranged from -190 to $-90{ }^{\circ} \mathrm{C}$ and pressure from 1 torr to 9000 torr.

Purities of product and raffinate are summarized in Figure 9. Both product and raffinate purities remained at better than $98 \%$ for all the rates tested. The high rate of 4 STP L/cycle is twice the rate of the $\mathrm{Pd} / \mathrm{k}-\mathrm{PFR}$ configuration. The raffinate purity of the $\mathrm{Pd} / \mathrm{k}-\mathrm{MS}$

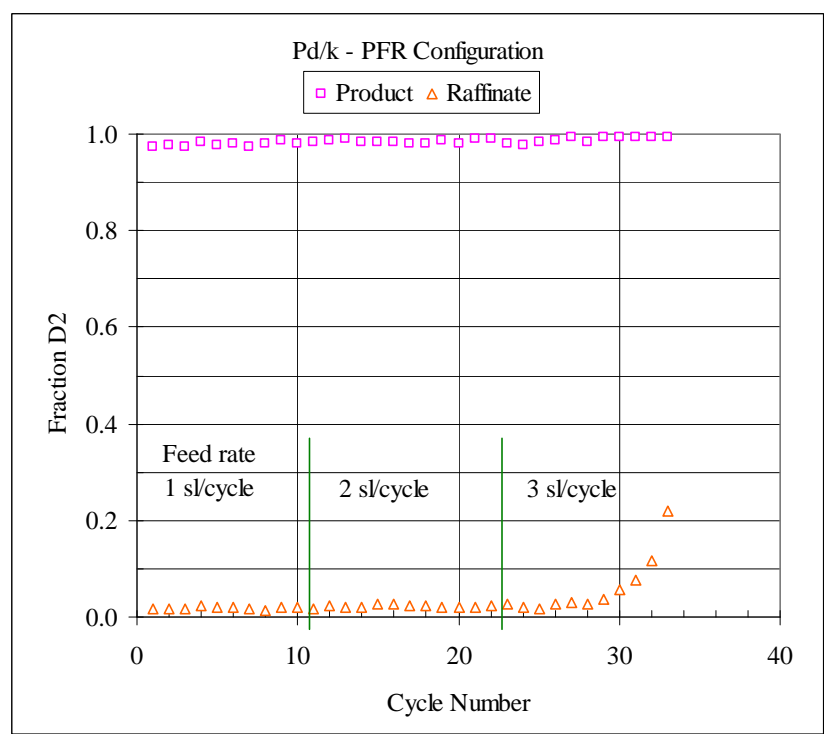

Figure 7. Product and raffinate purities of Pd/k-PFR configureation.

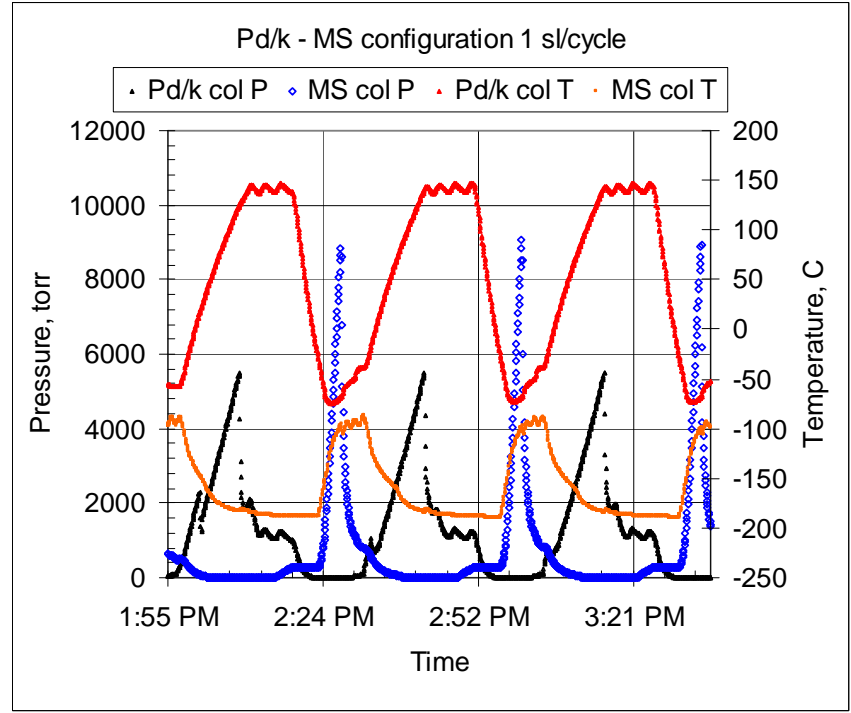

Figure 8. Temperature and pressure profiles of $\mathrm{Pd} / \mathrm{k}-\mathrm{MS}$ configuration.

configuration was also about $1 \%$ absolute better than the $\mathrm{Pd} / \mathrm{k}$-PFR configuration.

\section{SUMMARY AND CONCLUSIONS}

The thermal cycling absorption process was applied in two configurations: the Pd/k-PFR configuration and the $\mathrm{Pd} / \mathrm{k}-\mathrm{MS}$ configuration. The two configurations were tested side by side. The test results showed that the $\mathrm{Pd} / \mathrm{k}$ MS configuration is superior to the $\mathrm{Pd} / \mathrm{k}-\mathrm{PFR}$ configuration in that it doubled the throughput and produced better quality raffinate.

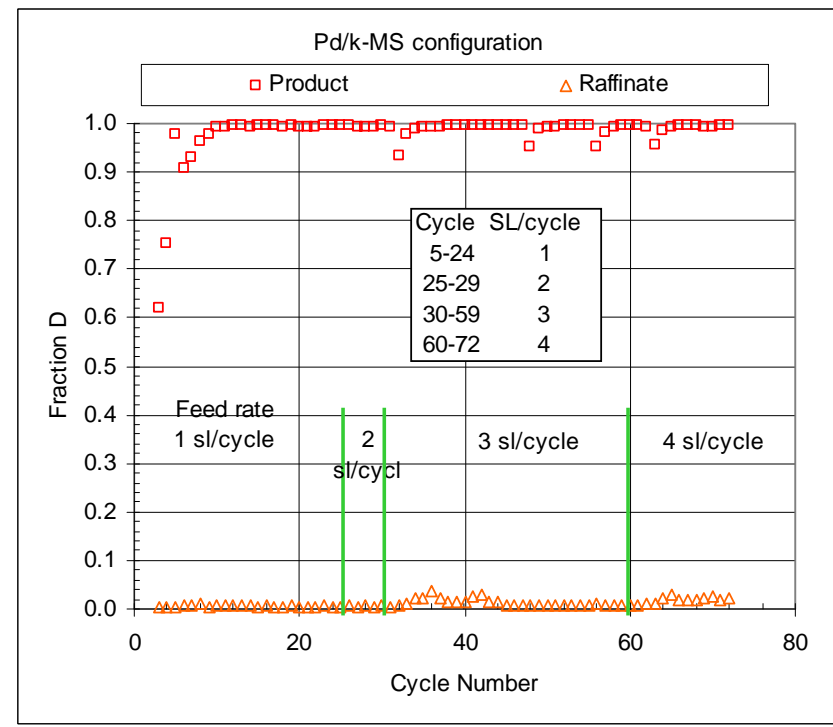

Figure 9. Product and raffinate purities of Pd/k-MS configuration. 


\section{ACKNOWLEDGMENTS}

This paper was prepared in conjunction with work accomplished under Contract No. DE-AC09-08SR22470 with the U.S. Department of Energy. Special thanks to Sharon Redd for her diligent laboratory support.

\section{REFERENCES}

1. M. W. LEE, "Tritium Separation Using Metal Hydrides”, Gordon Research Conference, Oxnard, CA (USA) February 10 (1986).

2. A. S. HOREN and M. W. LEE, "Metal Hydride Based Isotope Separation - Large-Scale Operations”, Fusion Technology, vol. 21, 282 (1992).

3. J. H. Scogin and A. S. Poore, "Startup and Operationof a Metal Hydride Based Isotope Separation System”, J. Fusion Technology, 28(3), 736 (1995).

4. L. K. HEUNG et al, "Next-Generation TCAP Hydrogen Isotope Separation Process", Fusion Science and Technology, vol. 54, 399, August (2008).

5. L. K. HEUNG, H. T. SESSIONS, X. XIAO, and H. L. MENTZER "Demonstration of The NextGeneration TCAP Hydrogen Isotope Separation Process", Fusion Science and Technology Vol. 56, 1471-1475, November (2009).

6. D. Basmadjian, "Adsorption Equilibria of Hydrogen, Deuterium, and Their Mixtures. Part 1", Canadian J. of Chem. Vol. 38, p141-148 (1960).

7. L. K. Heung, G. C. Staack, J. E. Klein and W. D. Jacobs, "Tests of Isotopic Separation Efficiency of Palladium Packed Columns", Fusion Science and Technology, Vol.54, 391-394, August (2008). 